\title{
Polylactic Acid Implant for Cranioplasty with 3-dimensional Printing Customization: A Case Report
}

\author{
Tedy Apriawan ${ }^{1,2 *}$, Khrisna Rangga Permana ${ }^{1,2}$, Ditto Darlan ${ }^{1,2}$, Muhammad Reza Arifianto ${ }^{1,2}$, Fitra Fitra ${ }^{1,2}$, Asra Alfauzi ${ }^{1,2}$, \\ Abdul Hafid Bajamal ${ }^{1,2}$ \\ ${ }^{1}$ Faculty of Medicine, Airlangga University, Surabaya, Indonesia; ${ }^{2}$ Department of Neurosurgery, Dr. Soetomo General Academic \\ Hospital, Surabaya, Indonesia
}

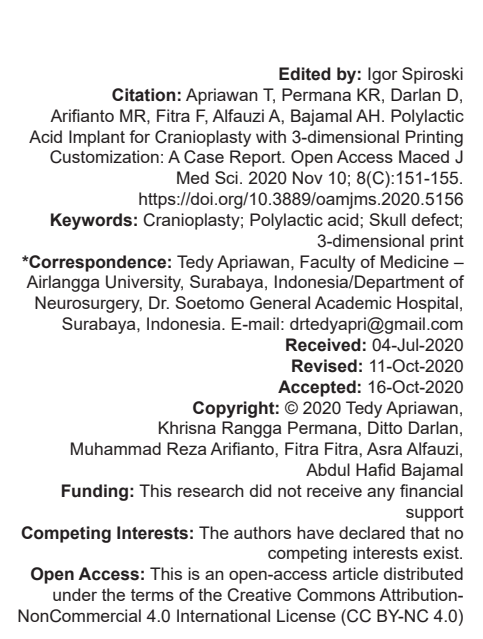

\begin{abstract}
BACKGROUND: Cranioplasty is aimed to restore the structure and function of the lost portion of the skull defect. Many materials can be used for cranioplasty, such as the bones of the patient (autograft), the bones of other patients (allograft), bones of animals (xenograft), or synthetic materials such as acrylic or titanium mesh. These materials are quite expensive and sometimes require complex processes. Manual shaping of material for cranioplasty is also quite time-consuming and prone to cause esthetic dissatisfaction. The author will discuss the case of using polylactic acid (PLA) implant with 3-dimensional (3D) printing customization as a cheap and accurate cosmetic solution for cranioplasty procedures.
\end{abstract}

CASE REPORT: We report 2 cases of skull defect underwent cranioplasty. The first case, female, 20-year-old, had a history of severe traumatic brain injury (TBI) and epidural hematoma. She underwent decompression craniotomy on the left frontotemporoparietal region of her skull. The second case, male, 46-year-old, had a history of spontaneous intracerebral hemorrhage due to arteriovenous malformation (AVM). He underwent decompression craniotomy on the right frontotemporoparietal region of her skull. Both the data of computerized tomography (CT) scan were reconstructed to get 3D model of skull defect. Prosthesis was made by 3D printer accordingly using PLA as material. There was no complication reported postoperatively and cosmetic satisfaction was obtained on both cases.

CONCLUSION: The use of PLA implant with 3D printing customization was proved to be cost-effective and good cosmetic satisfaction with no complication reported following cranioplasty procedure.

\section{Background}

Cranioplasty has a purpose to restore defect into a nearly close anatomical landmark of the skull to aim functional and cosmetic satisfaction [1]. Many materials can be used for cranioplasty, such as the bones of the patient (autograft), the bones of other patients (allograft), bones of animals (xenograft), or synthetic materials such as acrylic or titanium mesh [2]. Manual shaping of material for cranioplasty is also quite time-consuming and prone to cause esthetic dissatisfaction [3].

The most widely used autograft material is cranial bone from the patient itself, while materials such as tibia, ribs, scapula, and fascia, as well as the sternum and ileum, have begun to be abandoned because it is difficult to adjust bone flaps with defects in the skull [4]. Various other synthetic materials have been investigated to replace skull bone, such as hydroxyapatite, titanium mesh, alumina ceramics, and polyether ether ketone (PEEK). Each of these ingredients is proven safe to use, but all of them require a substantial cost [2], [5].
PLA is a Food and Drug Administration (FDA) - approved material that has been widely used for medical implants [6]. PLA can be used as customized 3-dimensional (3D) printing material. 3D printing technology itself has been widely used in industry and began to be used in the medical world [7]. 3D printing makes it possible to make implants with high accuracy for complex anatomy where manual shaping has weaknesses in accuracy and time consuming [8]. We present two cases of cranioplasty with PLA implant material with a $3 \mathrm{D}$ printer at our institution.

\section{Case Report}

The first case was a 20-year-old female with a skull defect in the left frontotemporal region. She underwent decompression craniotomy due to severe traumatic brain injury (TBI) and epidural hematoma lesion 4 years before admission. She actually had undergone cranioplasty but the bone was removed due 
to infection. The patient regularly did checkup in our hospital and decided to be performed cranioplasty due to cosmetic reasons. Physical examination revealed sufficient general conditions with a stable vital sign. No neurological deficit was reported. Head computed tomography (CT) scan revealed unilateral skull defect in the left frontotemporal region. Digital Imaging and Communications in Medicine (DICOM) data were processed to obtain $3 \mathrm{D}$ reconstruction model (Figure 1).

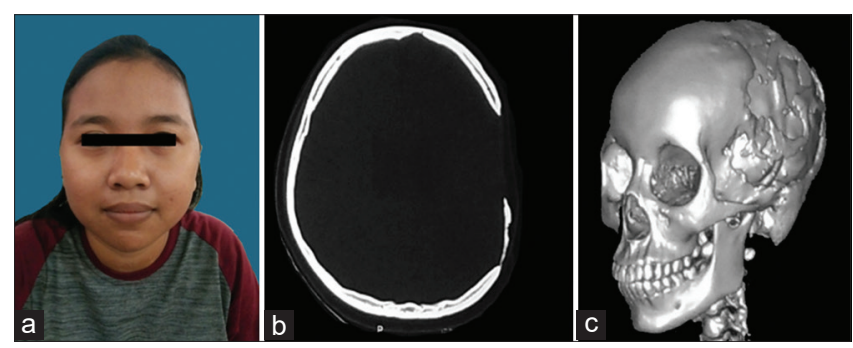

Figure 1: Pre-operative clinical photograph of a female with a skull defect in the left frontotemporal region (a) and head computed tomography with axial view of bone window (b) and 3-dimensional reconstruction (c)

The second case was a 46-year-old male with a skull defect in the right frontotemporal region. He underwent decompression craniotomy because of spontaneous intracerebral hemorrhage due to arteriovenous malformation (AVM) 1-year before admission. The patient came to our hospital to be performed cranioplasty due to esthetic reasons. Physical examination revealed sufficient general conditions with a stable vital sign. No neurological deficit was reported. Head CT scan and DICOM were obtained to render 3D reconstruction model (Figure 2).

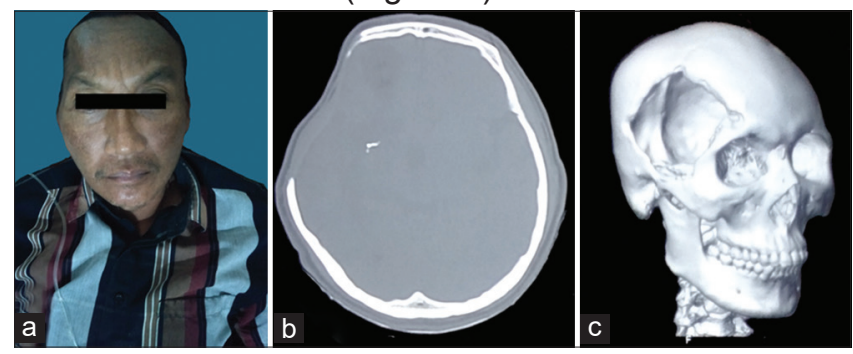

Figure 2: Pre-operative clinical photograph of a male with a skull defect in the right frontotemporal region (a) and head computed tomography with axial view of bone window (b) and 3-dimensional reconstruction (c)

In each case, 3D reconstruction was required from CT scan with each slice size of $1 \mathrm{~mm} \times 1 \mathrm{~mm}$. The DICOM file from the CT scan was used as a reference to create a three-dimensional model of the patient's craniofacial model using LightWave 3D (software by NewTek) program. Using Materialise Mimics (Software by Materialise, Belgium), the DICOM image was translated into a 3D model by Flash Print, software made by the company's 3D printer, Flashforge. The printer used was a fused deposition modeling (FDM) 3D printer (Hardware by Anycubic). The results of the reconstruction were then printed. The time need for $3 D$ reconstruction of skull/craniofacial phantom model was around $24-30 \mathrm{~h}$. The defects of decompression are also analyzed and measured to then make a negative mold model. The mold is based on the contour of the intact contralateral skull. The mold material used was PLA filament. The negative mold model was sterilized before in plasma system sterilization. The mold consisted of two pieces. During surgery, antibiotic was applied to the surface of the mold. Sterile PLA powder was mixed with sterile normal saline until its consistency became jellylike materials. PLA was applied to synthetic skull mold according to the size of the defect and was waited for $15 \mathrm{~min}$ for hardening. After the material was hardened, PLA implant was acquired. The implant was then placed over the defect and was fixed using miniplates and screws (Figure 3). A good reconstruction result was achieved and no complication was found during and after surgery.

Both patients were discharged $<1$ week after cranioplasty with the normal condition and no neurological deficit. Patients were advised to avoid direct impact on the site of surgery and maintain good hygiene. Both patients came regularly in bimonthly basis to do a medical checkup. No complication was reported and cosmetically satisfactory results were obtained. The cost was spent for 3D craniofacial model and negative mold was around 50-150 USD and for PLA was around 60-125 USD (conversion from author's currency, Rupiah).

\section{Discussion}

Skull defects can be caused by direct trauma or post-operative craniectomy of other causes. Therapeutic decompressive craniectomy (DC) operative surgery involves an increase in convex cranial bone flaps that are stored either in vivo (e.g., abdominal or thigh subcutaneous pouches) or in ex vivo media (cryogenically) and tissue bank). Cranioplasty aims to restore the defects in the skull to their original anatomical form which is close to normal anatomy so that they can provide protection to the brain and restore cosmetic aspects. Cranioplasty is challenging due to the various shapes, sizes, and complexity of the defect itself.

Cranioplasty involving frontal bone will be more difficult when compared with temporal and parietal bone due to its complex convexity anatomy. Frontal bone also has an orbital roof structure and more visible regions for cosmetic aspects impose more challenges for reconstruction [9].

The defect reconstruction with computerassisted 3D reconstruction allows more accurate anatomical form and it removes the time-consuming manual carving stage, although there is no clinical difference in outcome [10]. 3D reconstruction can provide the latest anatomical picture because the defect shape and soft tissue can change over time since DC is 

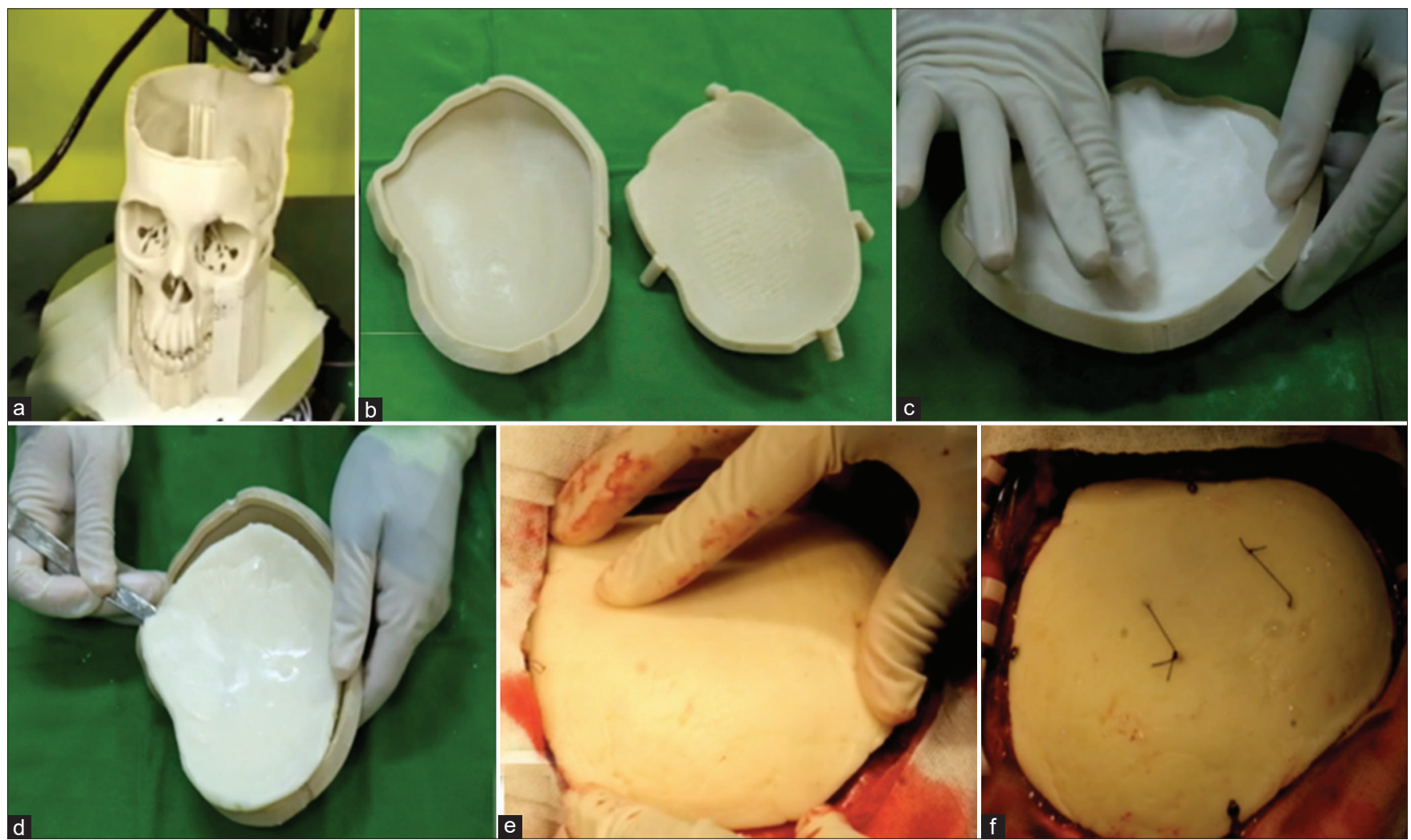

Figure 3: Implant remodeling process and placement scheme. Printing of skull phantom model with defects according to the patient's DICOM image (a); craniofacial model molds according to three-dimensional reconstruction (b); application of PLA to molds (c); synthetic skull formed according to the size of the defect (d); placement of synthetic skull implant made from PLA into the site of the defect (e and f)

done. These anatomical changes can prolong operating time because the implant becomes difficult to modify in-theatre [11].

Autograft cranioplasty is the best choice for economic reasons and compatibility with patients. However, in certain circumstances, autograft cranioplasty cannot be performed because of the destruction of the skull bone (e.g., due to trauma or invasion of the tumor). Various materials have been investigated as a basic component to replace the skull bone, such as hydroxyapatite, titanium mesh, alumina ceramics, and polyether ether ketone (PEEK). Each of these materials is proven safe to use, but all of them require a substantial cost.

In this study, we use polylactic acid (PLA) as materials for both the skull phantom model and mold. PLA is thermoplastic and biodegradable which nontoxic characteristic for the human body. PLA can be processed by injection molding so it is suitable for customized applications for 3D printing [12]. PLA has been used for a medical implant for the last decades due to its safety. PLA has a melting point in the range of $180-220^{\circ} \mathrm{C}$ and glass transition temperature about $57{ }^{\circ} \mathrm{C}$ [12], [13]. Due to its low melting point and glass transition temperature, PLA is not suitable for autoclave sterilization. Plasma system sterilization can be used for PLA which based on low-temperature hydrogen peroxide sterilization [14]. PLA had been approved as a safe material for the implant by the
US Food and Drug Administration (FDA) [6]. PLA degradation and absorption in vivo may vary depends on the size and shape of the plates, circulation, thickness of the soft tissue, and the transplant site. The smaller and less volume plates tend to have faster degradation and absorption [15], [16], [17]. Several studies stated PLA degradation and absorption in human body take up to $5-8$ years for the material to be absorbed [18], [19], [20].

The PLA cost was spent for 3D craniofacial model and negative mold was around 50-150 USD and for PLA was around 60-125 USD (conversion from author's currency, Rupiah) in our study. PEEK implant cost was approximately 10,450 USD, manually shaped titanium implant cost was 10,265 USD and hydroxyapatite implants cost was around 7840-8960 USD [21], [22], [23], [24]. These costs were significantly cheaper compared to other materials. In this study, we used 3D printer with cost around 250 USD and publicly provided software which are much cheaper than industrial hardware and software.

There was no complication reported postoperatively and cosmetic satisfaction was obtained on both cases in our study. PLA implants were reported to give accurate anatomical restoration. PLA implant for cranioplasty had the cranial index of symmetry around $96.2 \%$, it showed that PLA implant with computer-aided reconstruction was strongly accurate [25]. In a study with 22 consecutive patients undergoing cranioplasty 
with an implant using a desktop 3D printer, there was no sign of infection, implant rejection, wound dehiscence, or implant removal during the recovery period and 6-month follow-up [26].

\section{Conclusion}

The use of PLA implant with 3D printing customization was proved to be cost-effective and good cosmetic satisfaction with no complication reported following cranioplasty procedure. This technique can be an option for a cranioplasty procedure.

\section{References}

1. Mostafa Elkatatny AA, Eldabaa KA. Cranioplasty: A new perspective. Open Access Maced J Med Sci. 2019;7(13):2093101. https://doi.org/10.3889/oamjms.2019.489

PMid:31456832

2. Shah AM, Jung $H$, Skirboll $S$. Materials used in cranioplasty: $A$ history and analysis. Neurosurg Focus. 2014;36(4):E19. https:// doi.org/10.3171/2014.2.focus 13561 PMid:24684331

3. Sürme MB. Cranioplasty with preoperatively customized polymethyl-methacrylate by using 3-dimensional printed polyethylene terephthalate glycol mold. J Neurosci Neurol Disord. 2018;2:52-64. https://doi.org/10.29328/journal. jnnd.1001016

4. Aydin S, Kucukyuruk B, Abuzayed B, Aydin S, Sanus GZ. Cranioplasty: Review of materials and techniques. J Neurosci Rural Pract. 2011;2(2):162-7. https://doi org/10.4103/0976-3147.83584 PMid:21897681

5. Yu Q, Chen L, Qu Z, Zhang Y, Song T, Cui F. Skull repair materials applied in cranioplasty: History and progress. Transl Neurosci Clin. 2017;3(1):48-57. https://doi.org/10.18679/ cn11-6030/r.2017.007

6. Blasi P. Poly(lactic acid)/poly(lactic-co-glycolic acid)-based microparticles: An overview. J Pharm Invest. 2019;49:337-46. https://doi.org/10.1007/s40005-019-00453-z

7. Sharma S, Goel SA. 3D printing and its future in medical world. J Med Res Innov. 2018;3(1):e000141. https://doi.org/10.15419/ jmri.141

8. Chae MP, Rozen WM, McMenamin PG, Findlay MW, Spychal RT, Hunter-Smith DJ. Emerging applications of bedside 3D printing in plastic surgery. Front Surg. 2015;2:25. https://doi. org/10.3389/fsurg.2015.00025

PMid:26137465

9. Hatamleh MM, Cartmill M, Watson J. Management of extensive frontal cranioplasty defects. J Craniofac Surg. 2013;24(6):2018-22.

PMid: 24220395

10. Peel S, Eggbeer D, Burton H, Hanson H, Evans PL. Additively manufactured versus conventionally pressed cranioplasty implants: An accuracy comparison. Proc Inst Mech Eng H. 232(9):949-61. https://doi.org/10.1177/0954411918794718
11. Peel, S. \& Eggbeer, D. Additively manufactured maxillofacial implants and guides-Achieving routine use. Rapid Prototyp J. 2016;22(1):189-99. https://doi.org/10.1108/rpj-01-2014-0004

12. Pawar RP, Tekale SU, Shisodia SU, Totre JT, Domb AJ. Biomedical applications of poly(lactic acid). Recent Pat Regen Med. 2014;4(1):40-51. https://doi.org/10.2174/2210296504666 140402235024

13. Marek AA, Verney V. Photochemical reactivity of PLA at the vicinity of glass transition temperature. The photo-rheology method. Eur Polym J. 2016;81:239-46. https://doi.org/10.1016/j. eurpolymj.2016.06.016

14. Oth O, Dauchot C, Orellana M, Glineur R. How to sterilize 3D printed objects for surgical use? An evaluation of the volumetric deformation of 3D-printed genioplasty guide in PLA and PETG after sterilization by low-temperature hydrogen peroxide gas plasma. Open Dent J. 2019;13(1):410-7. https://doi. org/10.2174/1874210601913010410

15. Turvey TA, Bell RB, Tejera TJ, Proffit WR. The use of selfreinforced biodegradable bone plates and screws in orthognathic surgery. J Oral Maxillofac Surg. 2002;60(1):59-65. https://doi. org/10.1053/joms.2002.28274

PMid: 11757010

16. Böstman $\mathrm{O}$, Pihlajamäki $\mathrm{H}$. Clinical biocompatibility of biodegradable orthopaedic implants for internal fixation: A review. Biomaterials. 2000;21(24):2615-21. https://doi. org/10.1016/s0142-9612(00)00129-0 PMid:11071611

17. Choi HJ, Kim W, Youn S, Lee JH. Management of delayed infection after insertion of bioresorbable plates at the infraorbital rim. J Craniofac Surg. 2012;23(2):524-5. https://doi.org/10.1097/ scs.0b013e31824cd4de

PMid:22421862

18. Kim YY, Rhyu KW. Recompression of vertebral body after balloon kyphoplasty for osteoporotic vertebral compression fracture. Eur Spine J. 2010;19(11):1907-12. https://doi. org/10.1007/s00586-010-1479-6 PMid:20559850

19. Kim YM, Lee JH. Clinical courses and degradation patterns of absorbable plates in facial bone fracture patients. Arch Craniofac Surg. 2019;20(5):297-303. https://doi.org/10.7181/ acfs.2019.00409

PMid:31658793

20. Farah S, Anderson DG, Langer R. Physical and mechanical properties of PLA, and their functions in widespread applications-a comprehensive review. Adv Drug Deliv Rev. 2016;107:367-92. https://doi.org/10.1016/j.addr.2016.06.012

21. Staffa G, Nataloni A, Compagnone C, Servadei F. Custom made cranioplasty prostheses in porous hydroxy-apatite using 3D design techniques: 7 years experience in 25 patients. Acta Neurochir (Wien). 20007;149(2):161-70. https://doi.org/10.1007/ s00701-006-1078-9

PMid:17242849

22. Lemée JM, Petit D, Splingard M, Menei P. Autologous bone flap versus hydroxyapatite prosthesis in first intention in secondary cranioplasty after decompressive craniectomy: A French medico-economical study. Neurochirurgie. 2013;59(2):60-3. https://doi.org/10.1016/j.neuchi.2012.10.138

23. O'Reilly EB, Barnett S, Madden C, Welch B, Mickey B, Rozen S Computed-tomography modeled polyether ether ketone (PEEK) implants in revision cranioplasty. J Plast Reconstr Aesthet Surg. 2015;68(3):329-38. https://doi.org/10.1016/j.bjps.2014.11.001 PMid:25541423

24. Binhammer A, Jakubowski J, Antonyshyn O, Binhammer $P$. Comparative cost-effectiveness of cranioplasty implants. Plast Surg (Oakv). 2020;28(1):29-39. https://doi. org/10.1177/2292550319880922 
PMid:32110643

25. Tan ET, Ling JM, Dinesh SK. The feasibility of producing patient-specific acrylic cranioplasty implants with a low-cost 3D printer. J Neurosurg. 2016;124(5):1531-7. https://doi. org/10.3171/2015.5.jns 15119

PMid:26566203
26. Morales-Gómez JA, Garcia-Estrada E, Leos-Bortoni JE, Delgado-Brito M, Flores-Huerta LE, De La Cruz-Arriaga AA, et al. Cranioplasty with a low-cost customized polymethylmethacrylate implant using a desktop 3D printer. J Neurosurg. 2018;130:1-7. https://doi.org/10.3171/2017.12.jns 172574

PMid:29905512 